OPEN ACCESS

Edited by:

David Gonthier,

University of Kentucky, United States

Reviewed by:

Fang Ouyang,

Chinese Academy of Sciences

(CAS), China

Luis F. Goulao,

University of Lisbon, Portugal

Ryan Kuesel,

University of Kentucky, United States

*Correspondence:

Chelsea Megan Gowton cgowton@mail.ubc.ca

TORCID:

Chelsea Megan Gowton orcid.org/0000-0003-2443-0809

César Cabra-Arias orcid.org/0000-0002-7164-9785

Juli Carrillo

orcid.org/0000-0003-4673-2875

Specialty section:

This article was submitted to Agroecology and Ecosystem Services,

a section of the journal

Frontiers in Sustainable Food Systems

Received: 26 April 2021 Accepted: 13 September 2021 Published: 21 October 2021

Citation:

Gowton CM, Cabra-Arias C and Carrillo J (2021) Intercropping With Peppermint Increases Ground

Dwelling Insect and Pollinator Abundance and Decreases

Drosophila suzukii in Fruit. Front. Sustain. Food Syst. 5:700842. doi: 10.3389/fsufs. 2021.700842

\section{Intercropping With Peppermint Increases Ground Dwelling Insect and Pollinator Abundance and Decreases Drosophila suzukii in Fruit}

\author{
Chelsea Megan Gowton ${ }^{*}$, César Cabra-Arias ${ }^{\dagger}$ and Juli Carrillo ${ }^{\dagger}$ \\ Plant Insect Ecology and Evolution Lab, Faculty of Land and Food Systems, Centre for Sustainable Food Systems,

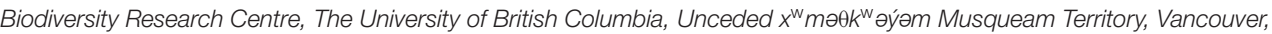 \\ BC, Canada
}

Intercropping can be used to reduce pest insects within agricultural systems, e.g., through deterring pests directly or by increasing habitat for their natural enemies. For example, plant produced volatile organic compounds (VOCs) can deter or confuse host-finding by insects through olfactory disruption. Drosophila suzukii is an invasive fruit fly of agricultural concern as it can lay its eggs in both ripening and fresh fruits and, uses olfactory cues to identify its wide range of host plants. Peppermint plants (Mentha $\times$ piperita) produce high levels of VOCs while growing and may, therefore, be suitable as an intercrop to reduce $D$. suzukii infestations in the field, as peppermint essential oil VOCs have previously been shown to deter $D$. suzukii in olfactory trials. We conducted a field intercropping experiment to evaluate the effectiveness of peppermint plants compared to traditional ryegrass/clover mixes in reducing $D$. suzukii oviposition in the field, and the effect of peppermint intercrops on other invertebrates. In the field, we monitored sentinel fruit baits weekly for $D$. suzukii infestation. Additionally, we monitored intercropping effects on the invertebrate community through weekly pitfall trap collection and through a pollinator point survey. We monitored for local, farm level presence of $D$. suzukii through apple cider vinegar traps within crop fields and along hedgerows and found high abundance of $D$. suzukii (>3,000 individuals trapped). Peppermint intercrops had fewer $D$. suzukii emerge from fruit baits and supported greater beneficial insect abundance (predators and pollinators) compared to ryegrass/clover. However, levels of D. suzukii were low across both intercrop types. Overall, we found that peppermint intercrops could be a potential aromatic intercrop used to reduce D. suzukii adult emergence from fruit compared to conventional ryegrass/clover mixes, however this trial should be replicated over multiple growing seasons, geographic locations, and host fruits. Furthermore, further study should determine the effects of the intercrop on the focal crop of interest.

Keywords: spotted wing drosophila (SWD), biological control, biodiversity, agroecosystem, organic, pest management 


\section{INTRODUCTION}

Increased plant diversity on farms can improve ecosystem services such as nutrient cycling, soil conservation, pollination, and pest control (Isbell et al., 2017). Within a cropping system, including two or more crops (e.g., polyculture, intercropping, etc.), or utilizing companion plants (e.g., insectary plants Brennan, 2013, 2016) can support pest control goals in a multitude of ways. For example, including multispecies plantings may disrupt the ability of pest insects to find their host plants through changes in visual, olfactory, and other sensory cues (Cook et al., 2007; Pickett et al., 2012, 2014). Increasing plant diversity on farm, including through the use of intercropping systems, can increase the diversity and availability of resources (e.g., habitat, nectar, and pollen) for beneficial and predaceous insects, potentially supporting topdown control of pest populations (Root, 1973; Tscharntke et al., 2002; Kruess, 2003). For intractable pests, in which other control options have limited utility (e.g., due to the development of insecticide resistance or the inaccessibility of the pest to pesticide application) or are otherwise restricted (e.g., to maintain organic certification and/or to avoid negative interactions with pollinators), intercropping may present a more sustainable option for growers (Brennan, 2013, 2016; Pickett et al., 2014).

Drosophila suzukii Matsumura (Diptera: Drosophilidae) is an invasive insect pest accidentally introduced to the US in 2008 and has since become widely distributed across fruit growing regions including the USA (Lee et al., 2012), Europe (Asplen et al., 2015), Mexico and South America (Deprá et al., 2014), and Canada (Walsh et al., 2011; Thistlewood et al., 2013). D. suzukii females possess a serrated ovipositor which allows them to lay eggs in a broad range of ripening and fresh fruits, leading to larval presence within harvested fruit (Walsh et al., 2011; Anfora et al., 2012). Finding more effective and sustainable means of control for D. suzukii is of utmost importance due to the substantial losses experienced in berry and small fruit industries (Asplen et al., 2015; Haye et al., 2016) and the intensive management required to maintain marketable fruit.

Common management practices to prevent and reduce $D$. suzukii infestations include pesticide sprays every 4-7 days (Bruck et al., 2011), which can have numerous non-target effects (Desneux et al., 2006). Growers typically rely on pesticide sprays consisting of pyrethroids, carbamates, and spinosyns which target adults, which represent only about $10 \%$ of the populations (Anfora et al., 2012), whereas larvae are generally protected within developing fruit and pupae fall and burrow in the ground (Woltz and Lee, 2017). In Canada, two organic pesticides are registered for D. suzukii management, of which only one (spinosyn) is effective at reducing D. suzukii damage to crops (Bruck et al., 2011). Overall, the organic sector is more impacted by $D$. suzukii infestation due to the limited availability of effective and economically-feasible D. suzukii control solutions (Iglesias and Liburd, 2017). Although growers may also use cultural management practices such as rapid harvesting, removing damaged and dropped fruit, and the use of exclusion netting to manage D. suzukii (Leach et al., 2018), these practices can be economically unfeasible or provide limited control (Iglesias and Liburd, 2017). Both organic and conventional growers are impacted by the evolution of pesticide resistance in D. suzukii populations (Gress and Zalom, 2019), necessitating alternative control options and spurring research into the use of intercropping systems for $D$. suzukii control.

Of note, some intercrops release volatile organic compounds (VOCs) which can function in the attraction and deterrence of insect pests (Miller and Cowles, 1990; Khan et al., 2008). Utilizing plant-produced VOCs may be a less intensive way to manage pests compared to conventional pesticide application (Desneux et al., 2006; Khan et al., 2008), or could provide supplementary control. Plant-produced VOCs may disrupt hostfinding behavior by either repelling or deterring pest insects from potential hosts (Miller and Cowles, 1990; Agelopoulos et al., 1999; Cook et al., 2007; Khan et al., 2008), or by attracting insects to traps (Burrack et al., 2015; Figueroa-Castro et al., 2017; Hasni et al., 2017). For example, VOCs from plant essential oils have been used to repel agricultural pests including codling moth (Cydia pomenella L.) (with oils of lavender, Lavandula officinalis L.; pennyroyal, Mentha pulegium L.; and cypress, Cupressus sempervirens L.) (Landolt et al., 1999), red bud borer midges [Resseliella oculiperda (Rubasaamen)] (with lavender essential oil, Lavandula angustifolia P. Mill.) (Van Tol et al., 2007) and western flower thrips [Frankliniella occidentalis (Pergande)] (with common thyme, Thymus vulgaris L. and winter savory, Satureja montana L.) (Picard et al., 2012). In the few instances where intercropping has been trialed in field systems, intercropping with high VOC-producing plants has been shown to reduce pests, either through direct repellent effects (e.g., Pickett et al., 2014) or through the attraction of natural enemies (Brennan, 2013, 2016). For example, intercropping maize with VOC-producing silverleaf desmodium (Desmodium uncinatum Jacq.) has been successful at reducing pests such as the stemborer moths (Chilo partellus Swinhoe) in sub-Saharan Africa (Khan et al., 2008; Vanlauwe et al., 2008; Pickett et al., 2014). Intercropping lettuce (Lactuca sativa L.) with sweet alyssum (Lobularia maritima L.) has also been successful at reducing currant-lettuce aphids (Nasonovia ribisnigri Mosley) by recruiting natural enemies such as hoverflies (Syrphidae) (Brennan, 2013); this pattern has also been observed in sweet alyssum intercropping of broccoli (Brassica oleracea L.) (Brennan, 2016). However, intercropping can also have neutral (Hodgkiss et al., 2019), or even positive effects on pest populations, e.g., through the creation of beneficial microhabitat that supports pest populations (Root, 1973). It is important to note that for intercropping practices to be successful, they must reduce pest populations while not impacting focal crop yield. Iverson et al. (2014) found diverse cropping systems, especially at high cropping densities, benefit pest biocontrol without affecting focal crop yield. However, they found that even when their results were consistent across geographical areas, the intercropping system could be affected by the type of plants used suggesting the need for intercrop trials with multiple plant types (Iverson et al., 2014). Furthermore, Letourneau et al. (2011) also found diversified cropping systems to benefit herbivore suppression 
through increased natural enemies, and that reductions in crop yield resulted from non-crop plants replacing those of agricultural importance.

Peppermint [Mentha x piperita, L. (pro. sp.)] is an aromatic crop for use in essential oil production as it yields high quantities of VOCs, including menthol (Santoro et al., 2011). In the laboratory, peppermint essential oil volatiles deterred D. suzukii adults up to 6 days after application (Renkema et al., 2016) and reduced adult emergence from pupae (Gowton et al., 2020). These results suggest that intercropping with volatile producing companion crops, such as peppermint, may similarly disrupt host finding or reproductive behavior of $D$. suzukii. Furthermore, growers may receive other benefits through intercropping practices such as diversified crops available to sell at market, reduction of other pests and weeds (Knörzer et al., 2010), and the attraction of beneficial insects. This reduction of pests by their natural enemies (i.e., predators and parasitoids) is expected to be more efficient in diversified crop habitats compared with simplified ones, as natural enemies may be more abundant in environments offering a greater diversity of prey/host species and microhabitats to exploit (Root, 1973).

Through a series of field assays at the University of British Columbia (UBC) Farm, we evaluated whether a peppermint intercrop could (1) reduce D. suzukii infestations in ripe fruit, (2) increase the number of beneficial ground dwelling invertebrates (potential pupal predators of D. suzukii), and (3) increase pollinators compared to the common alley groundcover of ryegrass and white clover.

\section{MATERIALS AND METHODS}

\section{Site Description}

On May 19, 2017, we initiated a field experiment at the Center for Sustainable Food Systems at UBC Farm (The University of British Columbia) to determine the efficacy of interplanting peppermint as a method to reduce $D$. suzukii infestations. UBC and UBC farm are located on the traditional, ancestral, and unceded territory of the $\mathrm{x}^{\mathrm{w}} \mathrm{m} \partial \theta \mathrm{k}^{\mathrm{w}} \partial y^{2} \partial \mathrm{m}$ Musqueam people, within a 90-year-old coastal hemlock forest (Centre for Sustainable Food Systems at UBC Farm, 2019). The UBC Farm is a 24-hectare, certified organic, diversified farm that grows over 200 varieties of fruits and vegetables, including blueberries and strawberries, common crop hosts of D. suzukii (Centre for Sustainable Food Systems at UBC Farm, 2019). The area surrounding UBC Farm includes alternative hosts of D. suzukii, such as elderberry (Sambucus L.), Himalayan blackberry (Rubus armeniacus Focke), salmonberry (Rubus spectabilis Pursh), trailing blackberry (Rubus ursinus Cham. \& Shchldl.), and thimbleberry (Rubus parviflorus Nutt). The majority of BC blueberry production occurs within the lower Fraser Valley, which produces $90 \%$ of Canada's highbush blueberries (AgriService BC, 2018). The closest berry production operations are $12.64 \mathrm{~km}$ from UBC Farm. However, unlike much of the blueberry growing region of the lower Fraser Valley, the UBC farm is located on Bose-Heron soil (non-agricultural soil) with a sandy loam texture, characterized by poor water and nutrient-holding capacity but high soil organic matter (SOM) content due to management practices (Krzic et al., 2015).

\section{On-Farm Monitoring of $D$. suzukii}

We monitored on-farm presence of D. suzukii with 10 apple cider vinegar (ACV) liquid bait traps located within hedgerows, 3 traps within a separate production planting of blueberries (Duke and Reka varieties) and 3 traps within a production planting of strawberries at the UBC Farm (Supplementary Figure 1). Each trap consisted of a $950 \mathrm{~mL}$ polypropylene deli container (Fabri$\mathrm{Kal}$ ) with ten $2.0 \mathrm{~mm}$ holes spaced $2.5 \mathrm{~cm}$ apart $10 \mathrm{~cm}$ from the top of the container filled with an ACV stock solution of $4-\mathrm{L}$ of store-bought apple cider vinegar mixed with $0.1 \mathrm{~g}$ unscented detergent (Alconox, Inc.), and $0.05 \mathrm{~g}$ instant yeast. We placed $200 \mathrm{~mL}$ of the ACV solution in the trap and hung the trap on a $1.20 \mathrm{~m}$ U-Post (Peak Products) and collected it weekly. From the ACV traps, D. suzukii were sorted from other drosophilids and bycatch, counted and sexed. We conducted ACV trapping from April 12th to October 25th, 2018.

\section{Experimental Plot Establishment at UBC Farm}

UBC Farm staff tilled the 31 by $7.5-\mathrm{m}$ site $(49.249845 \mathrm{~N},-123.237734 \mathrm{~W})$ prior to plot establishment in 2017. We obtained 36 Duke variety blueberry bushes (Vaccinium corymbosum L.) in $7.5 \mathrm{~L}$ pots (Sidhu Growers, Abbotsford, BC Canada). We sunk the pots into the ground at 1-m spacing (from pot center to pot center) to create two rows of 18 , consisting of 6 blocks. We chose to sink pots in the ground to standardize root zone availability within the blueberry plants and reduce potential competition between blueberry plants and intercrops. Each block contained two rows of three blueberry plants, separated by three $1.5 \times 5 \mathrm{~m}$ intercrop areas of either peppermint or ryegrass/clover control (Supplementary Figure 2).

Peppermint and ryegrass/clover blocks alternated within the field (not applied randomly), to reduce any density dependent effects of adjacent plots on volatile production and insect attraction. We used $1.0 \mathrm{~m}$ wide black landscaping cloth to create a buffer around the perimeter of the plot and between each intercrop block. On November 1, 2017, we seeded the control intercrop areas with white clover (Trifolium repens L.) (TerraLink Horticulture Inc.) and RichLawn Low-Maintenance Mix (TerraLink Horticulture Inc.) which contained a mixture of $20 \%$ perennial ryegrass (Lolium perenne), $30 \%$ hard fescue (Festuca ovina), and 50\% creeping red fescue (Festuca rubra), a common alleyway cover crop on local Lower Fraser Valley berry farms. We seeded the white clover at $0.15 \mathrm{~kg} / 92.90$ $\mathrm{m}^{2}$ and Low-Maintenance mix at a rate of $4.08 \mathrm{~kg} / 92.90$ $\mathrm{m}^{2}$. Within each peppermint plot, we transplanted 25 clonal plants propagated from cuttings from a commercially purchased peppermint [Mentha x piperita L. (pro. sp.), no variety given], grown in $3.8 \mathrm{~L}$ containers. Throughout the duration of the experiment, we maintained peppermint plots by weeding nonpeppermint by hand and by trimming and removing peppermint runners under the landscaping cloth. The ryegrass and clover plots did not receive mowing or weeding maintenance during the experimental period. Plots were watered using overhead 
sprinkler irrigation from April through the end of September for $15 \mathrm{~min}$, four times per day.

\section{Intercropping Effects on D. suzukii}

To test whether $D$. suzukii infestation differed between intercrop type (peppermint vs. traditional ryegrass/clover mix), we employed sentinel assays using fresh fruit baits within each intercrop type. In-field blueberry plants were too young in 2018 to produce enough mature fruit during this phase of the experiment to evaluate herbivory in a standardized method, however, the potted blueberry likely provided visual and olfactory cues of potential host plants.

To exclude bird and rodent damage or consumption of fruits, we constructed "fruit cages" (Supplementary Figure 3) to house fruit baits. Each week, we purchased fresh, organic blueberries to serve as bait for the fruit cages. We washed the fruit and placed five unblemished berries in each of the fruit cages. We placed a single baited cage at ground level within each of the $1.5 \times 5 \mathrm{~m}$ intercrop plots of the field site ( $n=9$ for peppermint, $n=9$ for ryegrass/clover control). Ground-based cages retained higher humidity (critical for D. suzukii survival) than traps placed at canopy level and $D$. suzukii will readily oviposit in both intact and abscised fruit. Baited cages remained in the field for $48 \mathrm{~h}$ to allow for wild D. suzukii oviposition. After the exposure period, berries were collected from each cage and placed in a $120 \mathrm{~mL}$ plastic solo cup (Uline, Model S-21201) with a perforated lid for airflow, and incubated in the lab for 2 weeks. Cages were reset with blueberries on a weekly basis and repeated over 18 weeks from May 1 to August 30, 2018. From September 11 to October 11, 2018, we followed the same protocol but used organic raspberries within the cages, due to commercial availability, and repeated this over a 5-week sampling period. Both blueberry and raspberry are commonly used in sentinel fruit assays with $D$. suzukii (Lee et al., 2011, 2016). Incubation in the lab occurred at ambient laboratory temperature and humidity $\left(\sim 23^{\circ} \mathrm{C}\right.$ and $\left.\sim 45 \% \mathrm{RH}\right)$ under cool white lights on a 16:8 h light:dark cycle. After 2 weeks of incubation, we counted all emerged drosophilids and identified adult $D$. suzukii and non-D. suzukii within samples. Additionally, each week we incubated 10 sets of "control" blueberries and raspberries ( 5 berries/incubation cup) - not placed in the fieldto estimate base levels of $D$. suzukii from store bought fruit.

On May 29, 2018, we observed chewing damage from slugs, ground beetles and wasps on blueberry baits, despite our mesh cages. We recorded the number of blueberries receiving chewing damage and brought the damaged blueberries back to the lab with any intact berries for the incubation period. We did not record raspberry damage due to the friable structure of the fruit itself after being exposed in the field.

\section{Pitfall Trap Survey}

We placed dry Vernon Pitfall Traps (Intko Supply Ltd.) in the center of plots along the top and bottom rows of the experimental planting on July 3, 2018 (Supplementary Figure 2). We collected pitfall traps weekly until a final sampling date on October 16, 2018 for a total of 16 weeks. For each sampling event, we froze individual pitfall samples for at least $24 \mathrm{~h}$, before identifying each sample to family level, except for Collembola which we identified to order (Supplementary Table 1). We identified the insects in the pitfall traps through morphological characterization. We started identifying the taxonomical orders by their most recognizable traits, and then we used dichotomous keys (Borror and White, 1970; Bland and Jaques, 2010) to identify specimens to taxonomical families. We supported our findings by comparing our samples with entomology photographic atlas (Castner, 2000), the photographic records from the Spencer Entomological Collection in the Department of Zoology at the University of British Columbia, and the specialized literature. For every family that we identified, we corroborated its taxonomic status and hierarchy with the Integrated Taxonomic Information System (ITIS) online database. To establish the functional groups to which those specimens belonged, we searched in the specialized literature, and we assigned our specimens to three categories: predators, herbivores, and detritivores (Supplementary Table 1).

\section{Pollinator Survey}

Midway through the growing season (July 13, 2018), we conducted a single pollinator survey across a subset of the experimental plots (six of each treatment) by sweep netting (Willmer and Stone, 2004). We counted all pollinators per plot including honeybees (Apidae, Hymenoptera), bumblebees, (Apidae, Hymenoptera), soldier beetles (Cantharidae, Coleoptera), butterflies (Hesperiidae, Lepidoptera), and hoverflies (Syrphidae, Diptera).

\section{Statistical Analysis}

All analyses were conducted in $\mathrm{R}$ version 3.6.1. (R Core Team, 2014) and figures were drawn using ggplot 2 (Wickham, 2016). We used the glmmTMB package to analyze each response variable (Brooks et al., 2017), except total pollinators which used a linear model available in base $\mathrm{R}$, and determined model fit through testing for overdispersion and comparing AIC scores (Blasco-Moreno et al., 2019, Bolker et al., 2009).

\section{On Farm Presence of $D$. suzukii}

In order to run Tukey post-hoc test to compare trap locations, we filtered ACV trap data by sample date to create two data frames. The first contains samples across all three trap locations (hedgerow, blueberry production field, or strawberry production field) from April 19, 2018 through August 16, 2018. We analyzed the total number of D. suzukii caught in ACV traps with time (as continuous) and trap location (hedgerow, blueberry production field, or strawberry production field) as fixed effects. We then ran a post-hoc Tukey test to determine main effect differences between all three trap locations.

After August 16, 2018 the strawberry production field was tilled by the growers, and we stopped ACV trap sampling in the strawberry production. The second data frame contains ACV traps samples from hedgerows and blueberry production field from August 23, 2018 through October 18, 2018. We analyzed the total number of D. suzukii caught in ACV traps with time (as continuous) and trap location (hedgerow, or blueberry production field) as fixed effects. As trap counts were zero heavy, 
we specified a zero inflated negative binomial II distribution for both models.

\section{Adult $D$. suzukii Emergence From Fruit Baits}

We analyzed the number of adult $D$. suzukii emerged from each fruit bait, with treatment (peppermint intercrop or ryegrass/clover control) and week (continuous) as fixed effects and plot as a random effect. As the emergence count data were zero heavy, we specified a zero inflated Poisson distribution for our model. Although we initially included fruit type (blueberry or raspberry) as a factor in the model, due to the abundance of zero counts, the fully parameterized model could not converge. Therefore, we excluded the fixed effect of fruit type to first evaluate the effects of intercropping across the full sampling period. We then filtered the data by fruit type which created two new data frames, the first being blueberry fruit bait samples and second raspberry fruit bait samples. In two separate models, we analyzed the number of adult $D$. suzukii emerged from (1) blueberry with treatment (peppermint intercrop or ryegrass/clover) and week (as continuous) as fixed effects; and (2) raspberry fruit bait with treatment (peppermint intercrop or ryegrass/clover) and week (as continuous) as fixed effects, and plot as a random effect, both with a Poisson distribution.

\section{Non-D. suzukii Damage of Berries}

We analyzed the number of blueberries (zero through five) experiencing non-D. suzukii insect damage using a generalized linear model with a zero inflated Poisson distribution with intercrop and date (as continuous) as fixed effects and plot as a random effect. Although these data were proportional, analyzing the total number of berries with damage provided better model fit due to the large number of zeros within the data.

\section{Insect Groups Collected From Pitfall Traps}

We classified insects captured within pitfall traps according to three functional groups: herbivore, predator, or detritivore (Supplementary Table 1). We analyzed pitfall trap samples (total insects, total predators, total herbivores (excluding D. suzukii), and total detritivores) using a generalized linear mixed model with intercrop (as categorical) and time (as continuous) as fixed effects and plot as a random effect. After assessing for overdispersion and normalcy, we fit our total insect model with a generalized Poisson distribution, total predator model with a zero inflated negative binomial I distribution, and the total herbivores and total detritivores models with a zero inflated negative binomial II distribution.

\section{Pollinator Survey}

We analyzed the total number of sampled pollinators using a linear model with intercrop as a fixed effect.

\section{RESULTS}

\section{On Farm Presence of $D$. suzukii}

Apple cider vinegar traps captured D. suzukii across the landscape at UBC Farm (Figure 1). We captured a total of
3,063 individual D. suzukii adults within our ACV traps during our sampling period. From April 19 to August 16, 2018, we captured more D. suzukii in hedgerows compared to blueberry and strawberry production fields [trap location: $X^{2}{ }_{(2,280)}=$ 48.10, $p<0.0001]$, and captures depended upon sample date $\left[X^{2}{ }_{(1,280)}=102.47, p<0.0001\right]$, and the interaction between trap location and sample date $\left[X^{2}{ }_{(2,280)}=7.93, p=0.02\right]$. After August 23, 2018, D. suzukii capture rates were higher in hedgerows than the blueberry production field [trap location: $\left.X_{(1,111)}^{2}=17.21, p<0.0001\right)$, and were dependent on sample date [sample date: $\left.X^{2}{ }_{(1,111)}=101.17, p<0.0001\right]$ and the interaction between sample date and trap location $\left[X^{2}{ }_{(1,111)}=\right.$ 9.64, $p=0.002$ ]. We first detected $D$. suzukii in monitoring traps on April 19, with increasing ACV trap captures until July 26, 2018 (mean D. suzukii/trap \pm SE: $24.4 \pm 6.7$ ) (Figure 1). During the month of August, we found decreased ACV trap captures of $D$. suzukii (Figure 1). The highest trapping of D. suzukii occurred on October 11, 2018 in traps located along the field hedgerows (mean D. suzukii/trap \pm SE: $72.8 \pm 13.89$ ) (Figure 1).

\section{Adult D. suzukii Emergence From Fruit Baits}

We observed low emergence rates of $D$. suzukii (between 0 and 5 flies per sample) from the fruit cages when using blueberries and raspberries as bait (Figure 2). Out of 414 berry bait samples, we recorded a total of 29 adult $D$. suzukii from 20 fruit bait samples. We observed our first emergence of D. suzukii on July 26, 2018 in ryegrass/clover intercrop (average flies/cage \pm SE: $0.22 \pm 0.12$ ) (Figure 2). When comparing emergence across all fruit types, $D$. suzukii emergence was lower in peppermint intercrops than in ryegrass/clover intercrops [intercrop: $X_{(1,408)}^{2}=5.00, p=0.02$ ], and increased through time [date: $X_{(1,408)}^{2}=15.71, p<0.0001$ ]. Intercrop and sampling time did not interact to influence $D$. suzukii emergence [intercrop $\times$ date: $X_{(1,408)}^{2}=0.09, p=0.77$ ].

When we restricted the analysis to only the fruit cages baited with blueberry, adult $D$. suzukii emergence increased through time [date: $X_{(1,320)}^{2}=6.78, p=0.01$ ], but did not differ between peppermint and ryegrass/clover intercrops [intercrop: $X_{(1,320)}^{2}=0.00, p=1.00$ ] or the interaction with sampling time [intercrop $\times$ date: $X_{(1,320)}^{2}=0.00, p=1.00$; Supplementary Figure 4]. However, zero D. suzukii emerged from blueberry bait placed in peppermint intercrops (Figure 2; Supplementary Figure 4). When we restricted our analysis to only those fruit cages baited with raspberry, adult $D$. suzukii emergence decreased through time [date: $X_{(1,85)}^{2}=17.25, p$ $<0.0001$ ], but emergence did not differ between intercrops [intercrop: $X_{(1,85)}^{2}=0.30, p=0.58$; Supplementary Figure 4] or depend upon an interaction between intercrop and sampling time [intercrop $\times$ date: $X_{(1,85)}^{2}=0.16, p=0.69$ ]. No D. suzukii emerged from the control berries that remained in the laboratory.

\section{Non-D. suzukii Damage of Berries}

Fruit damage by other herbivores did not differ between intercropping type or over time [intercrop: $X_{(1,246)}^{2}=0.55$, $p=0.46$; date: $\left.X_{(1,246)}^{2}=2.59, p=0.11\right]$. Damage by other 


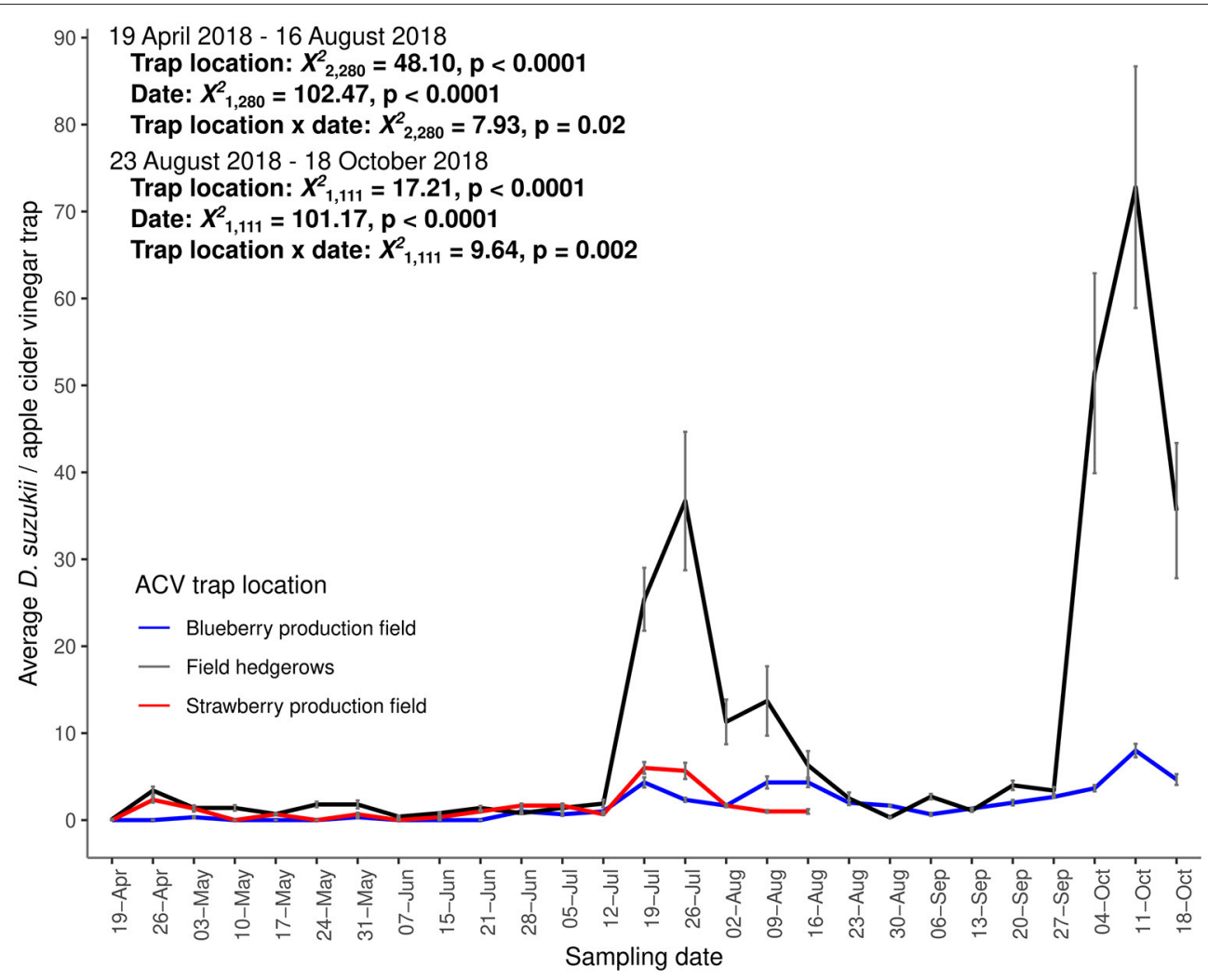

FIGURE 1 | Average counts of $D$. suzukii in apple cider vinegar traps in the blueberry production field (blue, $n=3$ ), strawberry production field (red, $n=3$ ) and field hedgerows (black, $n=10$ ) sampled weekly from April 19, 2018 to October 18, 2018. Means and standard error shown.

herbivores varied in the interaction between intercrop type and sampling time [intercrop $\times$ date: $X_{(1,246)}^{2}=5.04, p=0.03$ ] (Supplementary Figure 5).

\section{Insect Groups Collected From Pitfall Traps}

We captured 844 total insects within our pitfall traps, which included members of Hemiptera (Nabidae, Coreidae, Cercopidae, and Aphididae), Coleoptera (Staphylindae, Carabidae, Nitidulidae, Elateridae, Tenebrionidae, Curculionidae, Dermestidae, and Silphidae larvae), Hymenoptera (Braconidae, Cynipidae and Formicidae), Thysanoptera and Collembola. Total insect captures were affected by sampling date [date: $X_{(1,185)}^{2}=21.01, p<0.0001$; Figure 3A], but not intercrop type [intercrop: $X_{(1,185)}^{2}=0.34$, $p=0.56$; Figure $3 \mathbf{A}$ ] or its interaction with date [date $\times$ intercrop: $X_{(1,185)}^{2}=1.20, p=0.27$; Figure 3A].

We additionally sorted trapped insects into predators, nonD. suzukii herbivores, and detritivores (Supplementary Table 1) to determine the effects of intercrops on these functional groups. Date and intercrop significantly affected the total number of predators [date: $X_{(1,185)}^{2}=47.78, p<0.0001$; intercrop: $\left.X_{(1,185)}^{2}=5.55, p=0.02\right]$. We generally saw higher counts of predators in peppermint intercrop but this was variable across the sampling period [date $\times$ intercrop: $X_{(1,185)}^{2}=6.74, p=$ 0.01 ; Figure 3B]. Non-D. suzukii herbivores were more abundant in pitfall traps located in ryegrass/clover plots compared to peppermint intercrop plots [intercrop: $X^{2}{ }_{(1,185)}=20.53, p$ $<0.0001$; Figure 3C] with counts differing between sampling times [date: $X^{2}{ }_{(1,185)}=4.64, p=0.03$; however, there was no interaction between date $x$ intercrop: $X^{2}{ }_{(1,185)}=1.67, p$ $=0.20]$. We observed our highest non- $D$. suzukii herbivore counts on September 4, 2018 in our ryegrass/clover intercrops (average herbivores/trap \pm SE: $9.50 \pm 1.42$ ) but counts within our peppermint intercrop traps were only $1.67 \pm 0.34$ (average non-D. suzukii herbivores/trap $\pm \mathrm{SE}$ ). Total detritivores caught in pitfall traps was dependent on sampling time [date: $X^{2}{ }_{(1,185)}=$ $6.26, p=0.01$ ] but not intercrop type [intercrop: $X_{(1,185)}^{2}=0.07$, $p=0.80$; Figure 3D]. There was a significant interaction between sampling date and intercrop type [date $\times$ intercrop: $X_{(1,185)}^{2}=$ $10.17, p=0.001]$.

\section{Pollinator Survey}

Pollinators were more abundant in peppermint intercrops compared to ryegrass/clover plots [intercrop: $F_{(1,10)}=20.12, p=$ 0.002; Figure 4]. We observed honeybees, bumblebees, (Apidae, Hymenoptera), soldier beetles (Cantharidae, Coleoptera), butterflies (Hesperiidae, Lepidoptera), yellow jacket wasps (Vespidae, Hymenoptera), and hoverflies (Syrphidae, Diptera) visiting flowers while surveying the plots. In peppermint intercrops, we observed an average of $17.50 \pm 1.93$ pollinators 


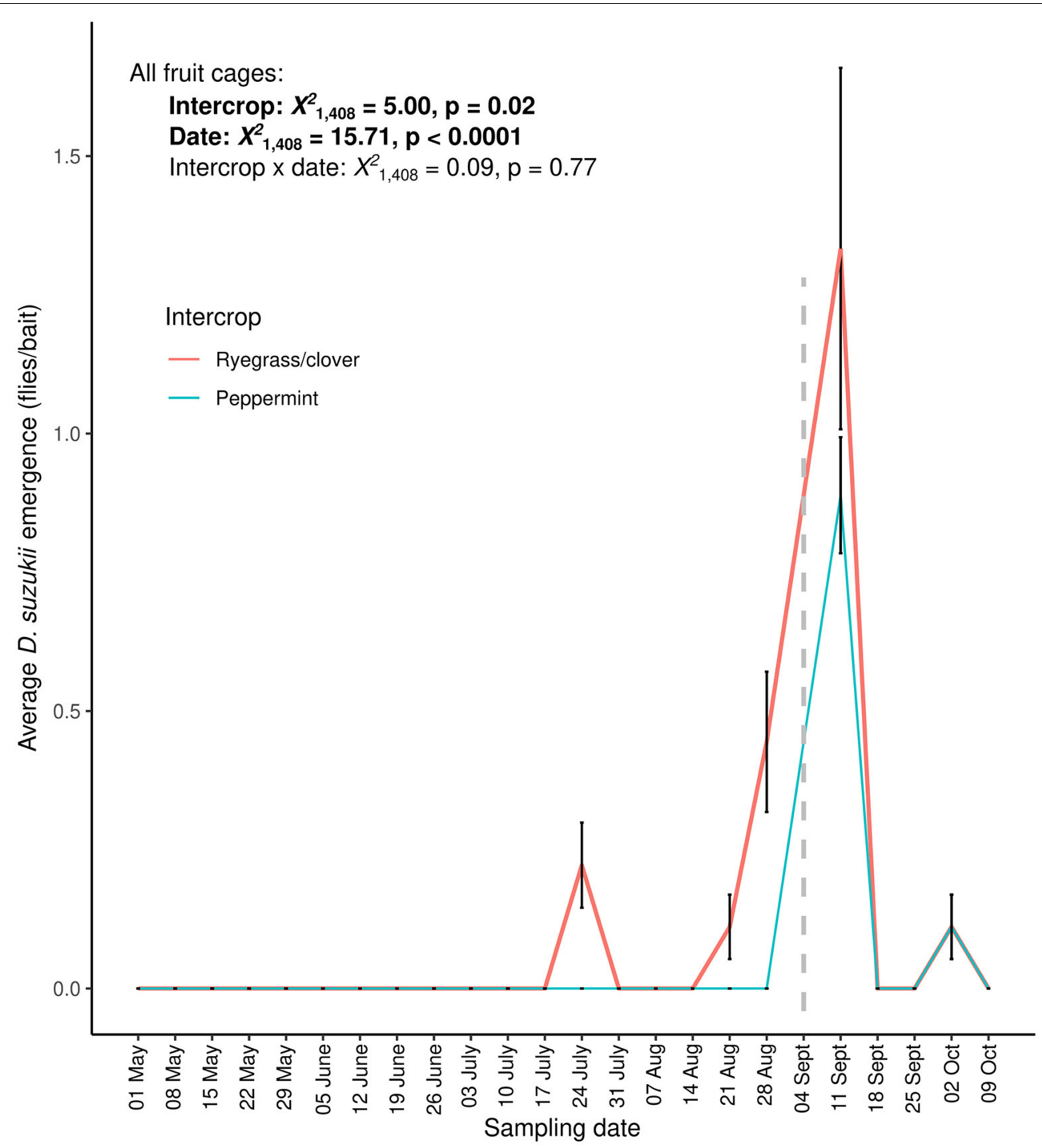

FIGURE 2 | D. suzukii emergence in weekly baited fruit baits with blueberries (May 3 to August 30, 2018) and raspberries (September 13 to October 11, 2018) in ryegrass/clover control (red) and peppermint (blue) intercrops. A dashed gray line on September 13, 2018 separates the two fruit types of fruit bait (blueberry and raspberry) used within the cages. Means and standard error shown.

per plot (average $\pm \mathrm{SE}$ ) compared to $3.00 \pm 1.40$ (average $\pm \mathrm{SE}$ ) within our ryegrass/clover control plots.

\section{DISCUSSION}

Intercropping with peppermint reduced the number of $D$. suzukii adults emerging from fruit over the course of the season compared to the conventional ryegrass/clover mix (Figure 2), suggesting the potential for volatile intercrops to be used for $D$. suzukii management. Encouragingly, we found zero D. suzukii in blueberry baits within the peppermint intercrop (Figure 2), despite high levels of D. suzukii on farm (Figure 1). Indeed, we had generally low emergence of $D$. suzukii from all fruit baits.
D. suzukii prefer post-harvest fruit compared to ripening fruit (Keesey et al., 2015), and we expected D. suzukii emergence from fruit baits at higher levels than we observed. It could be that the microclimate of our experiment did not adequately support D. suzukii. D. suzukii prefer moist environments (Tochen et al., 2016; Rendon and Walton, 2019) and D. suzukii activity density has been shown to increase along the edge of large forest habitats compared to habitats with less edge (Santoiemma et al., 2019). The UBC Farm is a diversified agro-ecosystem and is situated within a 90-year-old hemlock forest habitat. The hedgerows consist of a wide variety of understory plants which can promote microhabitats suitable for D. suzukii. While no formal survey was done for the current study, the hedgerows of the UBC Farm were planted in 2005-2006 (Centre for Sustainable Food Systems at UBC Farm, 2021) and offer a wide array of 


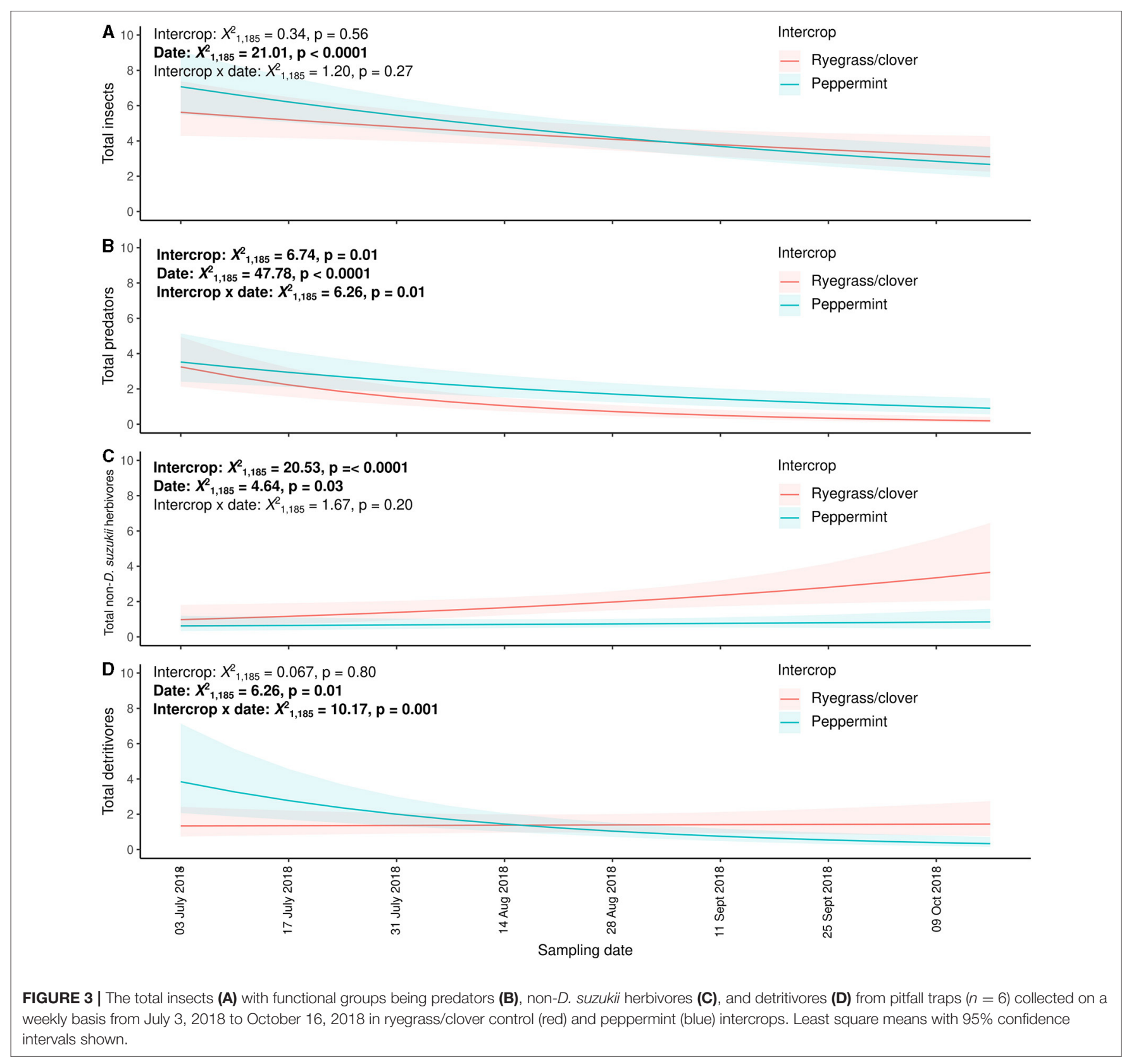

alternative hosts for D. suzukii including salmonberry (Rubus spectabilis Pursh), thimbleberry (Rubus parviflorus Nutt.), salal (Gaultheria shallon Pursh), currant (Ribes), dogwood (Cornus kousa F.buerger ex Hance), Oregon grape (Mahonia aquafolium [Pursh] Nutt.), elderberry (Sambucus) and red huckleberry (Vaccinium parvifolium Sm.) (Lee et al., 2011, 2015). While not intentionally planted, of important note is the invasive species, Himalayan blackberry (Rubus armeniacus Focke), which has also colonized the hedgerows and provides numerous fruit for D. suzukii infestation. These hedgerow locations contain hosts that are more preferential for $D$. suzukii than the blueberries used within our field experiment (Olazcuaga et al., 2019). Furthermore, the lower mainland of Vancouver experiences a dry season during the summer months (Canada Environment and Climate Change, 2021). D. suzukii abundance increases in high humidity habitats which likely were present within the shaded hedgerows (Diepenbrock and Burrack, 2016; Tochen et al., 2016). To access the irrigated cropping areas, D. suzukii would have to leave these more preferential forested habitats and travel across dry exposed landscape to reach these agricultural hosts.

It could be that VOCs from our peppermint intercrop permeated the entire experimental area and reduced $D$. suzukii levels compared to overall farm levels. We assumed that any effects of VOCs would occur in the immediate area of the fruit baits, and that experimental plots could be considered independent as each of our plots were separated 


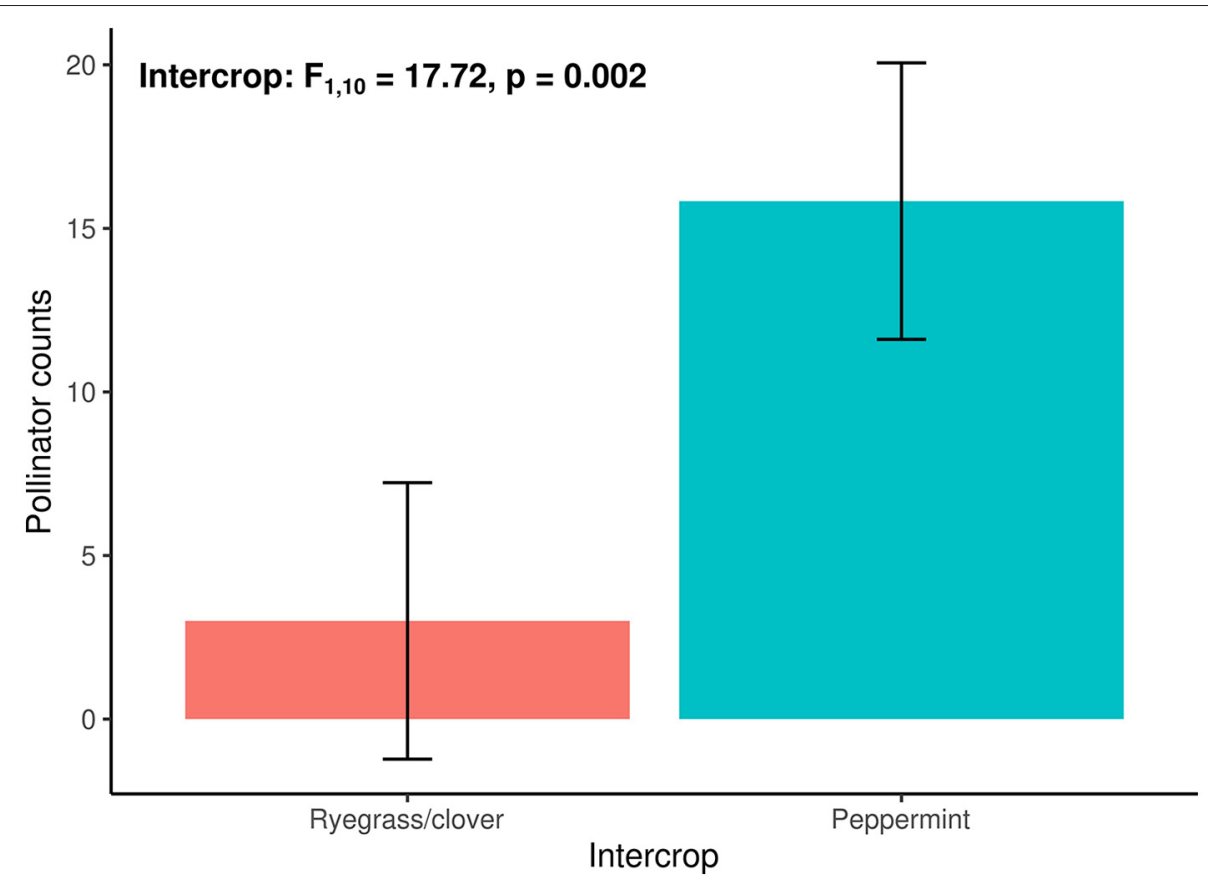

FIGURE 4 | Total pollinator counts per plot of ryegrass/clover control (red) and peppermint (blue) intercrops at one sampling event at 11:00 am. Least square means with $95 \%$ confidence intervals shown.

by one-meter landscaping cloth. However, during events that physically disturbed the intercrop (e.g., weeding or trimming), the smell of peppermint would diffuse a few meters away, however this appeared to occur infrequently. Nevertheless, this spatial effect may have completely disrupted D. suzukii host finding behavior within our whole experimental plot. Thus, it may be that our experimental spacing was not sufficient for $D$. suzukii to differentiate between fruit baits within the two intercropping types, resulting in overall low (or none) infestation rates in our fruit cages. However, because of the similarly low numbers of $D$. suzukii found in the blueberry production field and strawberry field on farm (Figure 1), it seems like the low numbers of $D$. suzukii observed within our experiment could be due to an overall preference of D. suzukii for hedgerows compared to crop fruit.

Pitfall trapping and a pollinator survey indicated that peppermint intercrops can support beneficial insects (Figures 3, 4), with higher levels of natural enemies and pollinators observed in peppermint compared to the conventional ryegrass/clover mix. Woltz and Lee (2017) found exposure to predators in a blueberry field to decrease the abundance of pupae between 61 and $91 \%$ and to reduce larval survival by $19-49 \%$, due to multiple predators, including ants and spiders (Woltz and Lee, 2017). Thus, increasing beneficial habitat, through peppermint intercropping, may further support D. suzukii pupae predation. For example, increasing floral resources and microhabitats increased counts of the beneficial hoverflies when intercropping Phacelia tanacetifolia (Benth.) in winter-wheat crops (Hickman and Wratten, 1996) and increased specialist parasitoids and parasitoid oviposition when intercropping L. maritima in grape vineyards (Begum et al., 2004, 2006). Intercropping collard greens with non-flowering parsley reduced aphid populations through recruitment of generalist predators but reduced specialist parasitoid emergence (Saldanha et al., 2019).

Despite only conducting a single pollinator survey, we consistently noticed higher pollinator activity in the peppermint intercrop throughout the baited fruit sampling period (C. Gowton, pers. obs.). This is to be expected as higher floral resources are associated with higher pollinator counts (Ebeling et al., 2008). For example, a greater number of pollinator visitors were observed in Mentha arvensis L. and Coriandrum sativum L. when intercropped in strawberries compared to Myosotis arvensis ([L.] Hill) or no intercropping treatments (Hodgkiss et al., 2019). While we did not specifically measure floral resources between the two intercrop treatments, we did conduct our survey while both clover and peppermint were flowering. However, to draw more accurate conclusions on how peppermint intercrops affect pollinator abundance and diversity, sampling should occur over multiple time periods and include floral surveys.

Economic costs associated with $D$. suzukii management are disproportionality experienced by organic compared to conventional growers (Farnsworth et al., 2017). Costs associated with increases in human labor associated with $D$. suzukii management in California organic raspberries decreased profit by 3.3\% (Farnsworth et al., 2017). Growers may invest in expensive cultural controls such as netting or plastic tunnels (Rogers et al., 2016) and/or include rapid harvesting and sanitation of infested or fallen fruits (Leach et al., 2018). Allowing fruit to ripen to the point where fruit drop can occur may exacerbate the issue as these host sites may increase subsequent $D$. suzukii populations 
and disease incidence (Walsh et al., 2011). However, removal of overripe or dropped fruit often involves increases in human labor for hand picking and removal of these potential oviposition sites. We did not observe an effect of intercrop on non-D suzukii herbivory (Supplementary Figure 5); however, we only recorded the presence or absence of herbivory damage on berries and did not quantify this measure further (e.g., percent berry damaged, weight removed). As consumed berries cannot be used by $D$. suzukii as an oviposition site, increased herbivory of fallen fruit could reduce D. suzukii levels within adjacent crops. However, further study is needed to confirm the economic viability of such an option, including costs of peppermint control and maintenance, as well as the variability of this approach across in blueberries and other fruit systems in orchards across different locations and across multiple growing seasons.

Pest management decisions may not have immediate effects on insect pest populations. The effects may be present over longer time scales where the new techniques work to reduce pest populations between generations. Maintaining current use of insecticides is not ideal for the long-term management of D. suzukii, as decreased susceptibility to Spinosad (an organic pesticide) (Van Timmeren et al., 2019) and inherited Spinosad tolerance have been observed in a Watsonville, California D. suzukii population (Gress and Zalom, 2019), suggesting the need for more management options. Moreover, current pesticide regimes used to reduce $D$. suzukii are not sustainable as increased insecticide use decreases beneficial arthropod abundance (Desneux et al., 2006).

We show that intercropping can increase the number of natural enemies within the intercrop area, however it is unclear if this translates to increased control within the crop. In a seminal example of intercrop attraction and support for natural enemies, Brennan demonstrated aphid control in lettuce intercropped with sweet alyssum, which functioned to attract hoverflies (Syrphidae, Diptera) (Brennan, 2013, 2016). Similarly, it may be that even marginal plantings of insectary plants such as peppermint could increase predator populations enough to reduce $D$. suzukii numbers within crops or populations through control of pupal predation (Woltz and Lee, 2017). Indeed, methods which target larval or pupal stages of D. suzukii affect a greater proportion of the population compared to current chemical methods which only target gravid females, as adult $D$. suzukii makeup only $8 \%$ of the total population (Emiljanowicz et al., 2014). After this experiment was completed, Abram et al. (2020) reported the presence of larval parasitoids Leptopilina japonica Novkovic \& Kimura and Ganaspis brasiliensis (Ihering) within the lower mainland in 2019 (Abram et al., 2020). This report includes capture of $L$. japonica at UBC Farm where we conducted this research (Abram et al., 2020). Further research is needed to determine the effects of floral resources (including peppermint) on the attraction of these parasitoids, but increasing habitat types (e.g., through intercropping) may increase natural enemies including parasitoids (Tscharntke et al., 2002; Kruess, 2003) such as L. japonica and G. brasiliensis parasitoids.

Although we managed the peppermint to prevent unwanted spread, there are several potential issues that require further study. Our experiment was not set up to test whether peppermint could increase competition for resources since our blueberries were grown in sunken pots and the intercrop was separated from the blueberries by landscaping fabric and had limited spread under the fabric. Since blueberries have a shallow rooting system contained within $0.4 \mathrm{~m}$ of the plant (Bryla and Strik, 2007), it is unlikely that competition for resources was an issue in this experiment. However, it should be noted that mint is characterized as an aggressive spreader without regular mowing (Lawrence, 2006) and further evaluation of its potential competitiveness with crops needs to be determined. In a field experiment near Simcoe, Ontario, Renkema et al. (2020) observed the lowest D. suzukii infestation rates in non-intercropped strawberries compared with trimmed and untrimmed peppermint intercropping (Renkema et al., 2020). That study was conducted later in the season when D. suzukii populations are at their highest and with more highly preferred fruits (strawberries). Critically, Renkema et al. (2020) observed a decreased in strawberry yield when peppermint intercrops were placed $0.6 \mathrm{~m}$ from strawberry plant center, and proposed this could be a result of shading and/or competition (Renkema et al., 2020).

Peppermint could also potentially result in an allelopathic effect which could reduce focal crop yield, as bioassays with mint leaf essential oils resulted in allelopathic effects due to menthone disrupting plant microtubule formation (Sarheed et al., 2020). However, further study is needed to determine if companion planting with peppermint will result in same allelopathic effects in the field. Mowing the peppermint to release VOCs during fruit ripening stages may help prevent and reduce further $D$. suzukii infestations, but could also increase potential allelopathic effects. Other potential economic factors to consider would be costs associated with maintaining a peppermint intercrop compared to the traditional grass/clover mixes as this was not addressed in our study but would be of concern for growers.

\section{CONCLUSION}

We sought to determine whether peppermint could be used as an aromatic intercrop to reduce $D$. suzukii infestations in berry crops. We conducted an intercropping trial at UBC Farm to determine whether peppermint can be implemented in the field to reduce natural $D$. suzukii infestations. Peppermint intercrops reduced D. suzukii adult emergence from fruit baits compared to conventional ryegrass/clover mixes, indicating the potential to use aromatic intercrops within perennial berry plantings.

However, our experiment should be replicated over multiple growing seasons, field sites and berry crops to determine whether intercropping with peppermint can be successfully adapted across geographic regions and different berry growers. Further experimentation should be conducted to determine whether peppermint intercrops can reduce D. suzukii infestations in ripening berry crops as this is a more important factor for growers. 


\section{DATA AVAILABILITY STATEMENT}

The datasets presented in this study can be found at: Center for Sustainable Food Systems at UBC Farm Dataverse doi: 10.5683/SP2/HMH80N.

\section{AUTHOR CONTRIBUTIONS}

CG and JC conceived the research. CG and CC-A collected data. CG, CC-A, and JC analyzed the data. CG made the figures and wrote the first draft of the manuscript. All authors designed experiments and worked on later manuscript versions.

\section{FUNDING}

This research (funding to JC) is part of Organic Science Cluster 3, led by the Organic Federation of Canada in collaboration with the Organic Agriculture Centre of Canada at Dalhousie University, supported by Agriculture and AgriFood Canada's Canadian Agricultural Partnership-AgriScience

\section{REFERENCES}

Abram, P. K., McPherson, A. E., Kula, R., Hueppelsheuser, T., Thiessen, J., Perlman, S. J., et al. (2020). New records of leptopilina, ganaspis, and asobara species associated with Drosophila suzukii in North America, including detections of japonica, L-No match found-brasiliensis, G. J. Hymenoptera Res. 78, 1-17. doi: $10.3897 /$ jhr.78.55026

Agelopoulos, N., Birkett, M. A., Hick, A. J., Hooper, A. M., Pickett, J. A., Pow, E. M., et al. (1999). Exploiting semiochemicals in insect control. Pesticide Sci. 55, 225-235. doi: 10.1002/(SICI) 1096-9063(199903)55:3<225::AID-PS887>3.0.CO;2-7

AgriService BC (2018). "Fast Stats 2016: British Columbia's Agrifood and Seafood Sector."

Anfora, G., Cini, A., and Ioriatti, C. (2012). A review of the invasion of Drosophila suzukii in Europe and a draft research agenda for integrated pest management. Bull. Insectol. 65, 149-60.

Asplen, M. K., Anfora, G., Biondi, A., Choi, D. S., Chu, D., Daane, K. M., et al. (2015). Invasion biology of spotted wing drosophila (Drosophila suzukii): a global perspective and future priorities. J. Pest Sci. 88, 469-494. doi: 10.1007/s10340-015-0681-z

Begum, M, Gurr, G. M., Wratten, S. D., Hedberg, P. R., and Nicol, H. I. (2006). Using selective food plants to maximize biological control of vineyard pests. J. Appl. Ecol. 43, 547-54. doi: 10.1111/j.1365-2664.2006.01168.x

Begum, M., Gurr, G., Wratten, S., Hedberg, P., and Nicol, H. (2004). The effect of floral nectar on the efficacy of the grapevine leafroller parasitoid, Trichogramma carvera. Int. J. Ecol. Environ. Sci. 30, 3-12. doi: 10.1016/j.biocontrol.2004.03.005

Bland, R. G., and Jaques, H. E. (2010). How to Know the Insects. Long Grove, IL: Waveland Press.

Blasco-Moreno, A., Pérez-Casany, M., Puig, P., Morante, M., and Castells, E. (2019). What does a zero mean? Understanding false, random and structural zeros in ecology. Methods Ecol. Evolut. 10, 949-959. doi: 10.1111/2041-210X.13185

Bolker, B. M., Brooks, M. E., Clark, C. J., Geange, S. W., Poulsen, J. R., Stevens, H., et al. (2009). Generalized linear mixed models: a practical guide for ecology and evolution. Trends Ecol. Evolut. 24, 127-135. doi: 10.1016/j.tree.2008. 10.008

Borror, D. J., and White, R. E. (1970). A Field Guide to the Insects of America North of Mexico. Boston, MA: Houghton Mifflin Company.

Brennan, E. B. (2013). Agronomic Aspects of strip intercropping lettuce with alyssum for biological control of aphids. Biol. Control 65, 302-311. doi: 10.1016/j.biocontrol.2013.03.017
Program. Additional funding was provided through an NSERC Discovery Award (to JC) and the BC Blueberry Council (to JC).

\section{ACKNOWLEDGMENTS}

This work was conducted on the traditional, ancestral, and unceded territory of the $\mathrm{x}^{\mathrm{w}} \mathrm{m} \partial \theta \mathrm{k}^{\mathrm{w}} \partial y$ ým Musqeaum People. We would like to thank Tim Carter and other UBC Farm staff for experimental plot establishment and assistance, A. Czajewska, A. Debonnel, S. Garcia, K. Ha, and L. Xiao for help with data collection and plot maintenance, and Q. Geissmann, and P. Girod for assistance with data analysis and comments on the manuscript.

\section{SUPPLEMENTARY MATERIAL}

The Supplementary Material for this article can be found online at: https://www.frontiersin.org/articles/10.3389/fsufs. 2021.700842/full\#supplementary-material

Brennan, E. B. (2016). Agronomy of strip intercropping broccoli with alyssum for biological control of aphids. Biological Control 97, 109-119. doi: 10.1016/j.biocontrol.2016.02.015

Brooks, M. E., Kristensen, K., van Benthem, K. J., Magnusson, A., Berg, C. W., Nielsen, A., et al. (2017). glmmTMB balances speed and flexibility among packages for zero-inflated generalized linear mixed modeling. $R$ J. 9, 378-400. doi: 10.32614/RJ-2017-066

Bruck, D. J., Bolda, M., Tanigoshi, L., Klick, J., Kleiber, J., Defrancesco, J., et al. (2011). Laboratory and field comparisons of insecticides to reduce infestation of Drosophila suzukii in berry crops. Pest Manage. Sci. 67, 1375-1385. doi: $10.1002 /$ ps.2242

Bryla, D. R., and Strik, B. C. (2007). Effects of cultivar and plant spacing on the seasonal water requirements of highbush blueberry. J. Am. Soc. Horticult. Sci. 132, 270-277. doi: 10.21273/JASHS.132.2.270

Burrack, H. J., Asplen, M., Bahder, L., Collins, J., Drummond, F. A., Guédot, C., et al. (2015). Multistate comparison of attractants for monitoring Drosophila suzukii (Diptera : Drosophilidae) in blueberries and caneberries. Environ. Entomol. 44, 704-712. doi: 10.1093/ee/nvv022

Canada Environment and Climate Change (2021). Canadian Climate Normals 1981-2010 Sation Data. Available online at: https://climate.weather.gc.ca/ climate_normals/station_select_1981_2010_e.html?searchType=stnName\& txtStationName=vancouver\&searchMethod=contains $\quad$ (accessed October 14, 2020).

Castner, J. L. (2000). Photographic Atlas of Entomology and Guide to Insect Identification. Gainesville, FL: Feline Press.

Centre for Sustainable Food Systems at UBC Farm (2019). "UBC Farm." About Us. 2019. Available online at: https://ubcfarm.ubc.ca/about/ (accessed November $16,2019)$.

Centre for Sustainable Food Systems at UBC Farm (2021). Hedgerow Plant Identification. Agroforestry at UBC Farm. Available online at: http:// agroforestry.ubcfarm.ubc.ca/ubc-farm-agroforestry-initiatives/hedgerows/ hedgerow-plant-identification/ (accessed February 04, 2020).

Cook, S. M., Khan, Z. R., and Pickett, J. A. (2007). The use of push-pull strategies in integrated pest management. Ann. Rev. Entomol. 52, 375-400. doi: 10.1146/annurev.ento.52.110405.091407

Deprá, M., Poppe, J. L., Schmitz, H. J., De Toni, D. C., and Valente, V. L. S. (2014) The first records of the invasive pest Drosophila suzukii in the South American continent. J. Pest Sci. 87, 379-383. doi: 10.1007/s10340-014-0591-5

Desneux, N., Decourtye, A., and Delpuech, J. (2006). The sublethal effects of pesticides on beneficial arthropods. Ann. Rev. Entomol. 52, 81-106. doi: 10.1146/annurev.ento.52.110405.091440 
Diepenbrock, L., and Burrack, H. J. (2016). Variation of within-crop microhabitat use by Drosophila suzukii (Diptera: Drosophilidae) in blackberry. J. Appl. Entomol. 141, 1-7. doi: 10.1111/jen.12335

Ebeling, A., Klein, A., Schumacher, J., Weisser, W. W., and Tscharntke, T. (2008). How does plant richness affect pollinator richness and temporal stability of flower visits? Oikos 117, 1808-1815. doi: 10.1111/j.1600-0706.2008. 16819.x

Emiljanowicz, L. M., Ryan, G. D., Langille, A., and Newman, J. (2014). Development, reproductive output and population growth of the fruit fly pest Drosophila suzukii (Diptera: Drosophilidae) on artificial diet. J. Econ. Entomol. 107, 1392-1398. doi: 10.1603/EC13504

Farnsworth, D., Hamby, K. A., Bolda, M., Goodhue, R. E., Williams, J. C., and Zalom, F. G. (2017). Economic analysis of revenue losses and control costs associated with the spotted wing drosophila, Drosophila suzukii (Matsumura), in the California raspberry industry. Pest Manage. Sci. 73, 1083-1090. doi: $10.1002 /$ ps. 4497

Figueroa-Castro, P., López-Martínez, V., Silva-García, F., and GonzálezHernández, H. (2017). Food attractants to increase pheromone-baited trap performance for Scyphophorus acupunctatus (Coleoptera: Dryophthoridae) in Mezcal Maguey. Florida Entomol. 100, 203-205. doi: 10.1653/024.100.0135

Gowton, C. M., Reut, M., and Carrillo, J. (2020). Peppermint essential oil inhibits Drosophila suzukii emergence but reduces Pachycrepoideus vindemmiae parasitism rates. Sci. Rep. 10:9090. doi: 10.1038/s41598-020-65189-5

Gress, B. E., and Zalom, F. G. (2019). Identification and risk assessment of spinosad resistance in a california population of Drosophila suzukii. Pest Manage. Sci. 75, 1270-1276. doi: $10.1002 /$ ps.5240

Hasni, N., Pinier, C., Imed, C., Ouhichi, M., Couzi, P., Chermiti, B., et al. (2017). Synthetic co-attractants of the aggregation pheromone of the date palm root borer Oryctes agamemnon. J. Chem. Ecol. 43, 631-643. doi: 10.1007/s10886-017-0862-8

Haye, T., Girod, P., Cuthbertson GS, A., Wang, X. G., Daane, K. M., Hoelmer, K. A., et al. (2016). Current SWD IPM tactics and their practical implementation in fruit crops across different regions around the world. J. Pest Sci. 89, 643-651. doi: $10.1007 / \mathrm{s} 10340-016-0737-8$

Hickman, J. M., and Wratten, S. D. (1996). Use of Phelia Tanacetifolia strips to enhance biological control of aphids by overfly larvae in cereal fields. J. Econ. Entomol. 89, 832-840. doi: 10.1093/jee/89.4.832

Hodgkiss, D., Brown, J. F. M., and Fountain, M. T. (2019). The effect of within-crop floral resources on pollination, aphid control and fruit quality in commercial strawberry. Agric. Ecosyst. Environ. 275, 112-122. doi: $10.1016 /$ j.agee.2019.02.006

Iglesias, L., and Liburd, O. E. (2017). Identification of biorational insecticides for managing spotted wing drosophila in organic blueberry production. Acta Horticult. 118, 283-292. doi: 10.17660/ActaHortic.2017.1180.38

Isbell, F., Adler, P. R., Eisenhauer, N., Fornara, D., Kimmel, K., Kremen, C., et al. (2017). benefits of increasing plant diversity in sustainable agroecosystems. J. Ecol. 105, 871-879. doi: 10.1111/1365-2745.12789

Iverson, A. L., Marín, L. E., Ennis, K. K., Gontier, D. J., Connor-Barrie, B. T., Remfert, J. L., et al. (2014). Do polycultures promote win-wins or trade-offs in agricultural ecosystem services? A meta-analysis. J. Appl. Ecol. 51, 1593-1602. doi: $10.1111 / 1365-2664.12334$

Keesey, I. W., Knaden, M., and Hansson, B. S. (2015). Olfactory specialization in Drosophila suzukii supports an ecological shift in host preference from rotten to fresh fruit. J. Chem. Ecol. 41, 121-128. doi: 10.1007/s10886-015-0544-3

Khan, Z. R., Midega AO, C., Amudavi, D. M., Hassanali, A., and Pickett, J. A. (2008). On-farm evaluation of the 'push-Pull' technology for the control of stemborers and striga weed on maize in Western Kenya. Field Crops Res. 106, 224-233. doi: 10.1016/j.fcr.2007.12.002

Knörzer, H., Müller, B. U., Guo, B., Graeff-Hönninger, S., Piepho, H., Wang, P., et al. (2010). Extension and evaluation of intercropping field trials using spatial models. Agron. J. 102, 102-1031. doi: 10.2134/agronj2009.0404

Kruess, A. (2003). Effects of landscape structure and habitat type on a plant-herbivore-parasitoid community. Ecography 26, 283-290. doi: $10.1034 / \mathrm{j} .1600-0587.2003 .03402 . \mathrm{x}$

Krzic, M., Bomke, A. A., Sylvestre, M., and Brown, S. J. (2015). Teaching sustainable soil management: a framework for using problem-based learning. Natural Sci. Educ. 44, 43-50. doi: 10.4195/nse2014.07.0015
Landolt, P. J., Hofstetter, R. W., and Biddick, L. L. (1999). Plant essential oils as arrestants and repellents for neonate larvae of the codling moth (Lepidoptera: Tortricidae). Environ. Entomol. 28, 954-960. doi: 10.1093/ee/28.6.954

Lawrence, B. M. (2006). Mint. The Genus Mentha. Boca Raton, FL: CRC Press.

Leach, H., Moses, J., Hanson, E., Fanning, P., and Isaacs, R. (2018). Rapid harvest schedules and fruit removal as non-chemical approaches for managing spotted wing drosophila. J. Pest Sci. 91, 219-296. doi: 10.1007/s10340-017-0873-9

Lee, Jana, C., Dalton, D. T., Swoboda-Bhattarai, K. A., Bruck, D. J., Burrack, H. J., Strik, B. C., et al. (2016). Characterization and manipulation of fruit susceptibility to Drosophila suzukii. J. Pest Sci. 89, 771-780. doi: 10.1007/s10340-015-0692-9

Lee, J. C., Bruck, D. J., Curry, H., Edwards, D., Haviland, D. R., Van Steenwyk, R. A., et al. (2011). The susceptibility of small fruits and cherries to the spotted-wing drosophila, Drosophila suzukii. Pest Manage. Sci. 67, 1349-1480. doi: $10.1002 /$ ps. 2225

Lee, J. C., Burrack, H. J., Barrantes, L. D., Beers, E. H., Dreves, A. J., Hamby, K. A., et al. (2012). Evaluation of monitoring traps for Drosophila suzukii (Diptera: Drosophilidae) in North America. J. Econ. Entomol. 105, 1350-1357. doi: $10.1603 / \mathrm{EC} 12132$

Lee, J. C., Dreves, A. J., Cave, A. M., Kawai, S., Isaacs, R., Miller, J. C., et al. (2015). Infestation of Wild and Ornamental Noncrop Fruits by Drosophila suzukii (Diptera: Drosophilidae). Ann. Entomol. Soc. Am. 108, 117-129. doi: 10.1093/aesa/sau014

Letourneau, D. K., Armbrecht, I., Rivera, B. S., Lerma, J. M., Carmona, E. J., Daza, M. C., et al. (2011). Does plant diversity benefit agroecosystems? A synthetic review. Ecol. Applicat. 21, 9-21. doi: 10.1890/09-2026.1

Miller, J. R., and Cowles, R. S. (1990). Stimulo-deterrent diversion: a concept and its possible application to onion maggot control. J. Chem. Ecol. 16, 3197-3212. doi: 10.1007/BF00979619

Olazcuaga, L., Rode, N. O., Foucaud, J., Facon, B., Ravigné V, Ausset, A., Leménager, N., et al. (2019). Oviposition preference and larval performance of Drosophila suzukii (Diptera: Drosophilidae), spotted-wing drosophila: effects of fruit identity and composition. Environ. Entomol. 48, 867-881. doi: $10.1093 / \mathrm{ee} / \mathrm{nvz} 062$

Picard, I., Hollingsworth, R. G., Salmieri, S., and Lacroix, M. (2012). Repellency of essential oils to Frankliniella occidentalis (Thysanoptera: Thripidae) as affected by type of oil and polymer release. J. Econ. Entomol. 105, 1238-1247. doi: 10.1603/EC11292

Pickett, J. A., Aradottir, G. I., Birkett, M. A., Bruce, T. J. A., Chamberlain, K., Khan, Z. R., et al. (2012). Aspects of insect chemical ecology: exploitation of reception and detection as tools for deception of pests and beneficial insects. Physiol. Entomol. 37, 2-9. doi: 10.1111/j.1365-3032.2011.0 0828.x

Pickett, J. A., Woodcock, C. M., Midega, C. A. O., and Khan, Z. R. (2014). Push-pull farming systems. Curr. Opin. Biotechnol. 26, 125-132. doi: 10.1016/j.copbio.2013.12.006

R Core Team (2014). R: A Language and Environment for Statistical Computing. Vienna: R Foundation for Statistical Computing.

Rendon, D., and Walton, V. M. (2019). Drip and overhead sprinkler irrigation in blueberry as cultural control for Drosophila suzukii (Diptera: Drosophilidae) in Northwestern United States. J. Econ. Entomol. 112, 745-752. doi: 10.1093/jee/toy395

Renkema, J. M., Frewin, A., and Hallett, R. H. (2020). Effects of interplanting peppermint (Lamiaceae) in Strawberry (Rosaceae) on Drosophila suzukii (Diptera: Drosophilidae) and seed-feeding pests (Hemiptera: Lygaeidae, Miridae, Rhyparochromidae). Canad. Entomol. 152, 575-586. doi: $10.4039 /$ tce.2020.34

Renkema, J. M., Wright, D., Buitenhuis, R., and Hallett, R. H. (2016). Plant essential oils and potassium metabisulfite as repellents for Drosophila suzukii (Diptera: Drosophilidae). Sci. Rep. 6:21432. doi: 10.1038/srep21432

Rogers, M. A., Burkness, E. C., and Hutchison, W. D. (2016). Evaluation of high tunnels for management of Drosophila suzukii in fall-bearing red raspberries : potential for reducing insecticide use. J. Pest Sci. 89, 815-821. doi: 10.1007/s10340-016-0731-1

Root, R. B. (1973). Organisation of plant-arthropod association in simple and diverse habitats, the fauna of collards (Brasica oleracea). Ecol. Monographs 43, 95-124. doi: 10.2307/1942161 
Saldanha, A. V., Gontijo, L. M., Carvalho, R. M. R., Vasconcelos, C. J., Corrêa, A. S., and Gandra, R. L. R. (2019). Companion planting enhances pest suppression despite reducing parasitoid emergence. Basic Appl. Ecol. 41, 45-55. doi: 10.1016/j.baae.2019.10.002

Santoiemma, G., Trivellato, F., Caloi, V., Mori, N., and Marini, L. (2019). Habitat preference of Drosophila suzukii across heterogeneous landscapes. J. Pest Sci. 92, 485-494. doi: 10.1007/s10340-018-1052-3

Santoro, M. V., Zygadlo, J., Giordano, W., and Banchio, E. (2011). Volatile organic compounds from rhizobacteria increase biosynthesis of essential oils and growth parameters in peppermint (Mentha piperita). Plant Physiol. Biochem. 49, 1177-1182. doi: 10.1016/j.plaphy.2011.07.016

Sarheed, M. M., Rajabi, F., Kunert, M., Boland, W., Wetters, S., Miadowitz, K., et al. (2020). Cellular base of mint allelopathy: menthone affects plant microtubules. Front. Plant Sci. 11:546345. doi: 10.3389/fpls.2020.546345

Thistlewood, H. M. A., Gibson, G. A. P., Gillespie, D. R., and Fitzpatrick, S. M. (2013). "Drosophila suzukii (Matsumura), spotted wing drosophila (Diptera: Drosophilidae)," in Biological Control Programs in Canada 2001-2012, eds P. G. Mason, and D. R. Gillespie (Wallingford: CABI Publishing), 152-155. doi: 10.1079/9781780642574.0152

Tochen, S., Woltz, J. M., Dalton, D. T., Lee, J. C., Wiman, N. G., and Walton, V. M. (2016). Humidity affects populations of Drosophila suzukii (Diptera: Drosophilidae) in blueberry. J. Appl. Entomol. 140, 47-57. doi: $10.1111 /$ jen.12247

Tscharntke, T., Steffan-Dewenter, I., Kruess, A., and Thies, C. (2002). Contribution of small habitat fragments to conservation of insect communities of grassland-cropland landscapes. Ecol. Appl. 12:354. doi: 10.2307/30 60947

Van Timmeren, S., Ashfaq Sial, A., Lanka, S. K., Spaulding, N. R., and Isaacs, R. (2019). Development of a rapid assessment method for detecting insecticide resistance in spotted wing drosophila (Drosophila suzukii Matsumura). Pest Manage. Sci. 75, 1782-1793. doi: 10.1002/ps.5341

Van Tol, R., Swarts, H. J., Van Der Linden, A., and Visser, J. H. (2007). Repellence of the red bud borer Resseliella oculiperda from grafted apple trees by impregnation of rubber budding strips with essential oils. Pest Manage. Sci. 63, 483-490. doi: 10.1002/ps.1374
Vanlauwe, B., Kanampiu, F., Odhiambo, G. D., De Groote, H., Wadhams, L. J., and Khan, Z. R. (2008). Integrated management of Striga hermonthica, stemborers, and declining soil fertility in Western Kenya. Field Crops Res. 107, 102-115. doi: $10.1016 /$ j.fcr.2008.01.002

Walsh, D. B., Bolda, M. P., Goodhue, R. E., Dreves, A. J., Lee, J., Bruck, D. J., et al. (2011). Drosophila suzukii (Diptera: Drosophilidae): invasive pest of ripening soft fruit expanding its geographic range and damage potential. J. Integrated Pest Manage. 2, G1-7. doi: 10.1603/IPM10010

Wickham, H. (2016). Ggplot2 Elegant Graphics for Data Analysis. Cham: Springer International Publishing. doi: 10.1007/978-3-319-24277-4_9

Willmer, P. G., and Stone, G. N. (2004). Behavioral, Ecological, and Physiological Determinants of the Activity Patterns of Bees, 347-466. doi: 10.1016/S0065-3454(04)34009-X

Woltz, J. M., and Lee, J. C. (2017). Pupation Behavior and Larval and Pupal Biocontrol of Drosophila suzukii in the Field. Biol. Control 110, 62-69. doi: 10.1016/j.biocontrol.2017.04.007

Conflict of Interest: The authors declare that the research was conducted in the absence of any commercial or financial relationships that could be construed as a potential conflict of interest.

Publisher's Note: All claims expressed in this article are solely those of the authors and do not necessarily represent those of their affiliated organizations, or those of the publisher, the editors and the reviewers. Any product that may be evaluated in this article, or claim that may be made by its manufacturer, is not guaranteed or endorsed by the publisher.

Copyright $\odot 2021$ Gowton, Cabra-Arias and Carrillo. This is an open-access article distributed under the terms of the Creative Commons Attribution License (CC BY). The use, distribution or reproduction in other forums is permitted, provided the original author(s) and the copyright owner(s) are credited and that the original publication in this journal is cited, in accordance with accepted academic practice. No use, distribution or reproduction is permitted which does not comply with these terms. 